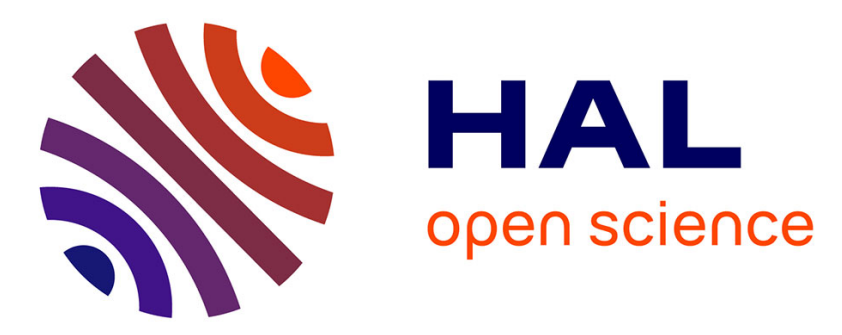

\title{
Effect of prolonged hypoxia in autotrophic conditions in the hydrogen production by the green microalga Chlamydomonas reinhardtii in photobioreactor
}

\author{
B. Degrenne, Jeremy Pruvost, J. Legrand
}

\section{- To cite this version:}

B. Degrenne, Jeremy Pruvost, J. Legrand. Effect of prolonged hypoxia in autotrophic conditions in the hydrogen production by the green microalga Chlamydomonas reinhardtii in photobioreactor. Bioresource Technology, 2011, 102 (2), pp.1035-1043. 10.1016/j.biortech.2010.08.009 . hal-02534168

\author{
HAL Id: hal-02534168 \\ https://hal.science/hal-02534168
}

Submitted on 17 Apr 2020

HAL is a multi-disciplinary open access archive for the deposit and dissemination of scientific research documents, whether they are published or not. The documents may come from teaching and research institutions in France or abroad, or from public or private research centers.
L'archive ouverte pluridisciplinaire HAL, est destinée au dépôt et à la diffusion de documents scientifiques de niveau recherche, publiés ou non, émanant des établissements d'enseignement et de recherche français ou étrangers, des laboratoires publics ou privés. 


\title{
Effect of prolonged hypoxia in autotrophic conditions in the hydrogen production by the green microalga Chlamydomonas reinhardtii in photobioreactor
}

\author{
B. Degrenne, J. Pruvost*, J. Legrand \\ Université de Nantes, CNRS, GEPEA UMR-CNRS 6144, Bd de l'Université, CRTT-BP 406, 44602 Saint-Nazaire Cedex, France
}

\section{A R T I C L E I N F O}

Keywords:

Hydrogen

Hypoxia

Microalgae

Chlamydomonas reinhardti

Photobioreactor

\begin{abstract}
A B S T R A C T
In the context of hydrogen production by the green alga Chlamydomonas reinhardtii, the control of light attenuation conditions is used to set-up anoxia under illuminated and autotrophic conditions, without affecting photosynthetic capacities of cells (as with sulphur deprivation or PSII inhibitors like DCMU). This paper presents a full description of the protocol where the incident photons flux density (PFD) is adapted during cultivation in order to obtain a sufficiently low illuminated fraction $\gamma$ under 0.25 leading to anoxic hydrogen producing conditions during several days. The protocol is validated in a torus-shape photobioreactor (PBR) revealing after few days of anoxic conditions a peak of hydrogen production ( $1.44 \mathrm{ml} \mathrm{H}_{2} / \mathrm{h} / \mathrm{l}$ of culture; [0.8-1.0] $\mathrm{ml} \mathrm{H}_{2} / \mathrm{h} / \mathrm{g}$ of dry weight biomass) concomitant with a decrease of biomass concentration, protein content and maximal photosynthetic yield. Effect of over-accumulating starch, as being known to increase hydrogen production by the $\mathrm{PS}_{\mathrm{II}}$-independent pathway, is also investigated.
\end{abstract}

\section{Introduction}

Photosynthetic hydrogen production by microalgae implies light and anoxic conditions (Benemann et al., 1973), the enzyme [Fe-Fe]-hydrogenase, responsible of hydrogen production, being inhibited in the presence of oxygen. This enzyme is the key element of hydrogen gas production under light because it reduces protons in hydrogen gas (Ghirardi et al., 2007) from the photosynthetic chain. Different protocols have been proposed to reach anoxia under light. Gaffron and Rubin (1942) have shown that after an anaerobiosis dark period adaptation, green microalgae were able to produce hydrogen. Benemann et al. (1973) used PS II inhibitors like DCMU (3-(3,4-dicholorophenyl)-1,1-dimethylurea) to stop oxygen production leading then to anoxic conditions. This idea was then relayed by several authors (Zhang and Melis, 2002; Fouchard et al., 2005; Cournac et al., 2002) enabling for example to better understand the two main metabolic hydrogen production pathways, namely the $\mathrm{PS}_{\mathrm{II}}$-dependent pathway as related to $\mathrm{PS}_{\mathrm{II}}$ activity supplying [Fe-Fe]-hydrogenase in electrons coming directly from water molecules splitting, and the $\mathrm{PS}_{\mathrm{II}}$-independent pathway linked to a catabolism of endogenous substrates like starch as an additional source of electrons. The drawback of inhibitors like DCMU is their irreversible effect on $\mathrm{PS}_{\mathrm{II}}$ activity resulting thus in a short term hydrogen production avoiding possible successive production cycles. Reversible protocols are obviously available.

\footnotetext{
* Corresponding author. Tel.: +33 (0)2 401726 68; fax: +33 (0)2 40172618. E-mail address: jeremy.pruvost@univ-nantes.fr (J. Pruvost).
}

Oxygen scavengers like sodium dithionite or glucose/glucose oxidize enzyme system can be for example added in the medium (Pow and Krasna, 1979; Kojima and Lin, 2004). Wykoff et al. (1998) have also shown that a sulphur starvation reduces PSII activity by $50 \%$ in the green microalga Chlamydomonas reinhardtii in 1 day. The same was measured with a phosphorus starvation but in 4 days. Achievement of anoxic conditions in continuous light intensity is also facilitated when increasing mitochondrial respiration, as for example when adding acetate in the growth medium (Melis et al., 2000; Degrenne et al., 2010). Because of its reversible effect, sulphur-deprivation protocol allows developing several cycles of hydrogen production (Melis, 2002; Kosourov et al., 2005). Guo et al. (2008) have shown that five cycles of hydrogen photoproduction could be conducted by adding CCCP (carbonylcyanide $m$-chlorophenylhydrazone) in the medium, after dark anaerobiosis adaptation. With the same aim of anoxic conditions achievement under light, Markov et al. (2006) used high light intensity $\left(2000 \mu \mathrm{mol} \mathrm{m}^{-2} \mathrm{~s}^{-1}\right)$ during a brief period of $15-30 \mathrm{~min}$ to photoinhibit $\mathrm{PS}_{\mathrm{II}}$ activity while maintaining a stable $\mathrm{PS}_{\mathrm{I}}$ activity so as to lead to hydrogen production. Makarova et al. (2007) combined impaired $\mathrm{PS}_{\mathrm{II}}$ activity with sulphur deprivation. Hamada et al. (2003) proposed to use light with specific spectral distribution having wavelengths higher than $680 \mathrm{~nm}$ not in the energetic gap of $\mathrm{PS}_{\mathrm{II}}$ (Emerson effect), resulting thus in a stop of oxygen emission leading to an hydrogen production by $\mathrm{PS}_{\mathrm{II}}$-independent pathway.

It must be stated that most of the hydrogen producing protocols are lead on a Tris Acetate Phosphate (TAP) medium, a widely used growth medium for $C$. reinhardtii but containing acetate. As an 
organic carbon source, acetate decreases photosynthetic capacities as well as it affects respiration rate (Heifetz et al., 2000; Endo and Asada, 1996). This facilitates achievement of anoxic conditions. This was recently shown by authors that if adequate light conditions in a photobioreactor (PBR) were applied, a continuous hydrogen production could be set-up by operating the PBR in chemostat mode with a medium containing acetate (Degrenne et al., 2010).

Recently, studies have focused on the possibility to reach anoxia under light in autotrophic conditions. Tsygankov et al. (2006) have combined sulphur deprivation with a decrease of incident photons flux density (PFD) to minimize oxygen production by $\mathrm{PS}_{\mathrm{II}}$ during hydrogen production phase. Moreover, variations in PFD to optimize starch accumulation allowed reaching higher hydrogen productivity due to $\mathrm{PS}_{\mathrm{II}}$-independent pathway (Tolstygina et al., 2009). Although the evident interest in working in autotrophic conditions $\left(\right.$ no $\mathrm{CO}_{2} \mathrm{re}-$ lease due to acetate degradation), productivities were found nevertheless lower than in mixotrophic conditions, with medium containing acetate (Kosourov et al., 2007). When associated to sulphur deprivation, the production on TAP medium allows reaching the highest productivities actually reported in literature with a flow-rate of $3.5 \mathrm{ml} \mathrm{H}_{2} / \mathrm{h} / \mathrm{l}$ of culture (Melis et al., 2000).

The aim of this work will be to investigate a simple way of maintaining anoxic conditions under light to induce hydrogen production by $C$. reinhardtii. This will be based on a rigorous control of light transfer conditions in the culture volume. As it is well-known, biomass productivity of photosynthetic microorganisms in any culture vessel is highly related to light attenuation conditions in the culture volume, because of the high need in light energy for photosynthetic growth, and of the high attenuation involved by cells pigmentation. As shown by Takache et al. (2010), PBR biomass productivity for eukaryotic cells as $C$. reinhardtii is found highly linked to the illuminated fraction (named $\gamma$ that represents the repartition in PBR volume between light and dark zones. Those authors demonstrated also that even if all the light should be absorbed in the culture volume to obtain a full conversion of incoming light, requesting thus a sufficiently high biomass concentration, a dark zone in the PBR revealed to have a negative effect on PBR productivity due to mitochondrial respiration. Biomass and oxygen productions being directly linked in photosynthetic growth, this conclusion will be extended here to the case of anoxia establishment in illuminated culture. The effect of prolonged anoxic conditions in strictly autotrophic conditions will be especially considered. Interest of a previous over-accumulation of starch will also be tested.

\section{Methods}

\subsection{Strain}

Wild type $C$. reinhardtii strain $137 \mathrm{AH}$ was gathered from culture collection of French Atomic Energy Center (Cadarache, France). Microalgae were incubated in Erlenmeyer at $25^{\circ} \mathrm{C}$ and $100 \mu \mathrm{mol} \mathrm{m}^{-2} \mathrm{~s}^{-1}$ in standard TAP medium. Before each experiments, cells were centrifuged (2000 rpm, $5 \mathrm{~min}$ and $20^{\circ} \mathrm{C}$ ) and pellet was suspended into a fresh new medium. Except when said in the text, the microorganism was cultivated in an autotrophic medium (minimum medium for growth-MMG) with the following composition ( $\mathrm{g} \mathrm{L}^{-1}$ ): $\mathrm{NH}_{4} \mathrm{Cl}, 1.45 ; \mathrm{MgSO}_{4} \cdot 7 \mathrm{H}_{2} \mathrm{O}, 0.28 ; \mathrm{CaCl}_{2} \cdot 2 \mathrm{H}_{2} \mathrm{O}$, $0.05 ; \mathrm{KH}_{2} \mathrm{PO}_{4}, 0.61 ; \mathrm{NaHCO}_{3}, 1.68$, with $1 \mathrm{ml}$ of Hutner's trace elements solution. This medium composition assumes no nutrient limitation until at least $3 \mathrm{~g} / \mathrm{l}$ for dry mass concentration.

\subsection{Photobioreactor description}

Experiments were conducted in a lab-scale torus-shape PBR which was already described elsewhere (Fouchard et al., 2008). It is equipped with gas mass flow-meters (Bronkhorst) in PBR inlets and outlet and a mass spectrometer (QMS, 200, Pfeiffer Vacuum) to measure outlet gas composition. This allows an online analysis of produced gas $\left(\mathrm{O}_{2}, \mathrm{CO}_{2}, \mathrm{H}_{2}\right)$. The torus PBR is of 1.51 working volume and has an optical path of $L=4 \mathrm{~cm}$ giving a specific illuminated area $\left(a_{\mathrm{s}}=1 / L\right)$ of $25 \mathrm{~m}^{-1}$. The PBR is made in stainless steel (type $316 \mathrm{~L}$ ), except the optical surface (front side) in transparent material (polycarbonate). Mixing is realised using a marine impeller. PBR is equipped with sensors like $\mathrm{pH}$, temperature (Mettler Toledo Inpro 3253SG/120/Pt100) and dissolved oxygen (Mettler Toledo Inpro 6800 Series $\mathrm{O}_{2}$ sensors). The photobioreactor was sterilized with steam $\left(105^{\circ} \mathrm{C}\right.$ for $20-25 \mathrm{~min}$ ) by using a steam generator (Maxi Vapor Plus, Bieffe, France).

With respect to light attenuation, this PBR can be regarded as in the more general group of "flat panel" type, presenting one-dimensional light attenuation along the depth of culture $z$ perpendicular to the optical flat surface (see Pottier et al., 2005 for details). The torus PBR was illuminated using 1500 white LEDs (Light Emitting Diodes, NSPW500CS, NICHIA) enabling PFD variation by simple voltage adjustment. PFD was measured using a plane cosine quantum sensor (Li-COR Li-190-SA, Lincoln, NE) which measures photosynthetically active radiation (PAR) in the $400-700 \mathrm{~nm}$ waveband received in a $2 \pi$ solid angle. PFD was measured on the back side of the optical surface to take into account light attenuation crossing this surface. For all experiments in PBR, a temperature of $25^{\circ} \mathrm{C}$ and a $\mathrm{pH}$ of 7.5 were controlled by air blowing and $\mathrm{CO}_{2}$ injection, respectively.

\subsection{Analysis}

\subsubsection{Biomass dry weight}

For biomass dry weight measurement, dependent on cells concentration, 5-15 ml of algal suspension were placed on a pre-dried glass-fiber filter (Whatman GF/F) at $110^{\circ} \mathrm{C}$ during $24 \mathrm{~h}$. After drying, filter was reweighed and dry weight was calculated.

\subsubsection{PSII activity}

Photosynthetic yield was measured with a WaterPam chlorophyll fluorometer (Walz, Germany). After a period of dark adaptation of $15 \mathrm{~min}$, a saturating pulse $\left(583 \mu \mathrm{mol}\right.$ photons $\left.\mathrm{m}^{-2} \mathrm{~s}^{-1}\right)$ was applied to measure the maximal $\mathrm{PS}_{\mathrm{II}}$ yield ( maximal yield $=F_{\mathrm{v}} / F_{\mathrm{m}}$ ).

\subsubsection{Proteins, total sugar and starch content analysis}

Proteins were quantified with the Lowry et al. (1951) using the Folin phenol reagent. Total sugar content was determined by the phenol-sulphuric acid method of Dubois et al. (1956). Starch analysis was performed using a method slightly modified from Klein and Betz (1978) described by Fouchard et al. (2005).

\subsubsection{Nutrient concentration measurements}

Ammonium, phosphate and sulphate concentrations were measured using anionic chromatography (DIONEX-120, IonPac AS12A anionic column) to verify that no limitations with respects to these compounds were achieved. Eluant was a solution of $270 \mathrm{mM}$ $\mathrm{Na}_{2} \mathrm{CO}_{3}$ and $30 \mathrm{mM} \mathrm{NaHCO}$ with a flow of $1.5 \mathrm{ml} / \mathrm{min}$.

\section{Theoretical consideration}

\subsection{The illuminated fraction $\gamma$}

Biomass productivity in a PBR is a function of incident PFD (noted $q_{0}$ ), its specific illuminated area (noted $a_{\mathrm{s}}$ ) and of the illuminated fraction $\gamma$ (Cornet and Dussap, 2009; Takache et al., 2010). PFD and $a_{\mathrm{s}}$ are common parameters usually employed in PBR studies. Due to the direct dependence of photosynthesis to light 
received, it is also well-known that PBR productivity is linked to light attenuation conditions in the culture volume. This can be represented by the illuminated fraction $\gamma$ (Cornet and Dussap, 2009; Cornet et al., 1992; Takache et al., 2010). Schematically, the culture volume can be delimited in two zones, namely an illuminated and a dark zone. Partitioning is obtained regarding the irradiance-field that represents light distribution in the culture volume. The transition from light to dark zones in the PBR is defined using the irradiance of compensation $G_{\mathrm{c}}$ corresponding to the minimum value of irradiance in order to obtain a positive photosynthetic growth rate (the so-called "compensation point"), that is also the same as having oxygen release by photosynthesis that compensates for its consumption by respiration. In autotrophic conditions, this value has been evaluated to $G_{\mathrm{c}}=10 \pm 3 \mu \mathrm{mol} \mathrm{m}^{-2} \mathrm{~s}^{-1}$ for $C$. reinhardtii (Takache et al., 2010). Determination of $G_{\mathrm{c}}$ location in the reactor requires radiative transfer to be modelled. This was already obtained and described for the torus PBR case in previous works (Pottier et al., 2005; Takache et al., 2010), including the case of hydrogen production (Degrenne et al., 2010). For the torus PBR responding to the one-dimensional hypothesis in Cartesian geometry, light attenuation occurs only along the depth of culture $z$. The illuminated fraction $\gamma$ is then given by the depth of culture where $G_{c}$ is obtained as follows (see Degrenne et al., 2010 or Takache et al., 2010 for details):

$\gamma=\frac{z_{\mathrm{c}}}{L}$

with $z_{\mathrm{c}}$ the compensation point in the culture depth $Z$, as defined by $G\left(z_{\mathrm{c}}\right)=G_{\mathrm{c}}$.

\subsection{Relation between the illuminated fraction and oxygen production}

The $\gamma$ fraction defines the volume in which the irradiance-field is higher than the irradiance of compensation $G_{c}$. This enables to write the oxygen volumetric production rate averaged on a PBR as the sum of two integral terms with light and dark zones characterizing different local kinetic production rates $r_{\mathrm{O}_{2}}$ as defined by (Cornet et al., 1992):

$\left\langle r_{\mathrm{O}_{2}}\right\rangle=\gamma \frac{1}{V_{1}} \iiint_{V_{1}} r_{\mathrm{O}_{2}, 1} \cdot d V+(1-\gamma) \frac{1}{V_{\mathrm{d}}} \iiint_{V_{\mathrm{d}}} r_{\mathrm{O}_{2}, \mathrm{~d}} \cdot d V$

with $V_{1}$ and $V_{\mathrm{d}}$, the illuminated and dark volumes, respectively.

Each integrand involves a kinetic production rate for light $\left(r_{\mathrm{O}_{2}, 1}\right)$ and dark $\left(r_{\mathrm{O}_{2}, \mathrm{~d}}\right)$ volumes, respectively. Because of the definition of the $G_{\mathrm{c}}$ value used to determined both illuminated and dark zones, in the case of eukaryotic cells which present mitochondrial respiration, the local kinetic rate $r_{\mathrm{O}_{2}, \mathrm{l}}$ used for the illuminated zone is positive, while $r_{\mathrm{O}_{2} \text {,d }}$ used for the dark zone is negative. As a consequence, the averaged value $\left\langle r_{\mathrm{O}_{2}}\right\rangle$ determined on the PBR volume will decrease when increasing the second integrand in Eq. (2), that is the same as decreasing the illuminated fraction value $\gamma$. As a consequence, the oxygen volumetric production rate averaged on the entire PBR (as represented by $\left\langle r_{\mathrm{O}_{2}}\right\rangle$ ) is a function of the illuminated fraction $\gamma$. The maximum value of $\left\langle r_{\mathrm{O}_{2}}\right\rangle$ will be obtained for the exact value $\gamma=1$ (that is the so-called luminostat regime) and decreasing the value $\gamma$ will decrease $\left\langle r_{\mathrm{O}_{2}}\right\rangle$ down to negative value when tending to $\gamma=0$. As a result, the oxygen production rate in the PBR $\left\langle r_{\mathrm{O}_{2}}\right\rangle$ can be controlled by simply adjusting the $\gamma$ value. As it will be shown in this study, this will be sufficient to achieve and maintain anoxic conditions in the culture volume in illuminated and autotrophic conditions.

\subsection{Setting anoxic conditions by controlling the illuminated fraction $\gamma$}

The aim is to achieve anoxic conditions under light by only changing the PFD, as a simple operating parameter directly modifying light radiative transfer conditions in the culture volume. As a

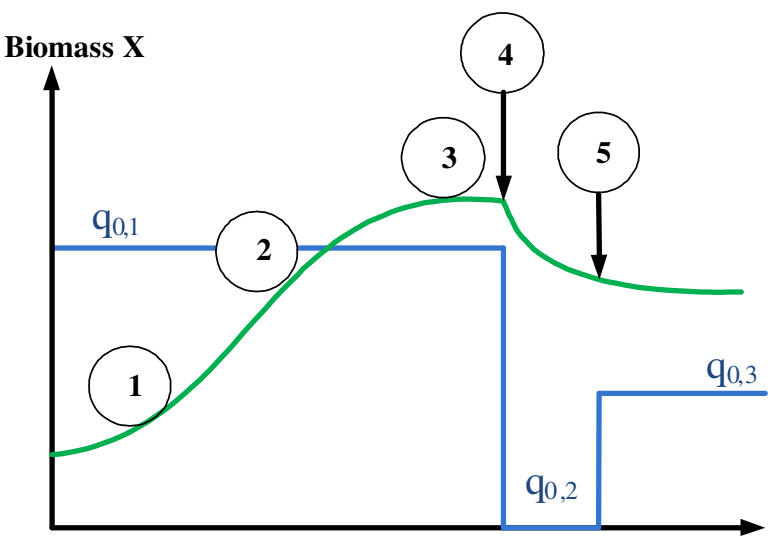

Time $\mathrm{t}$
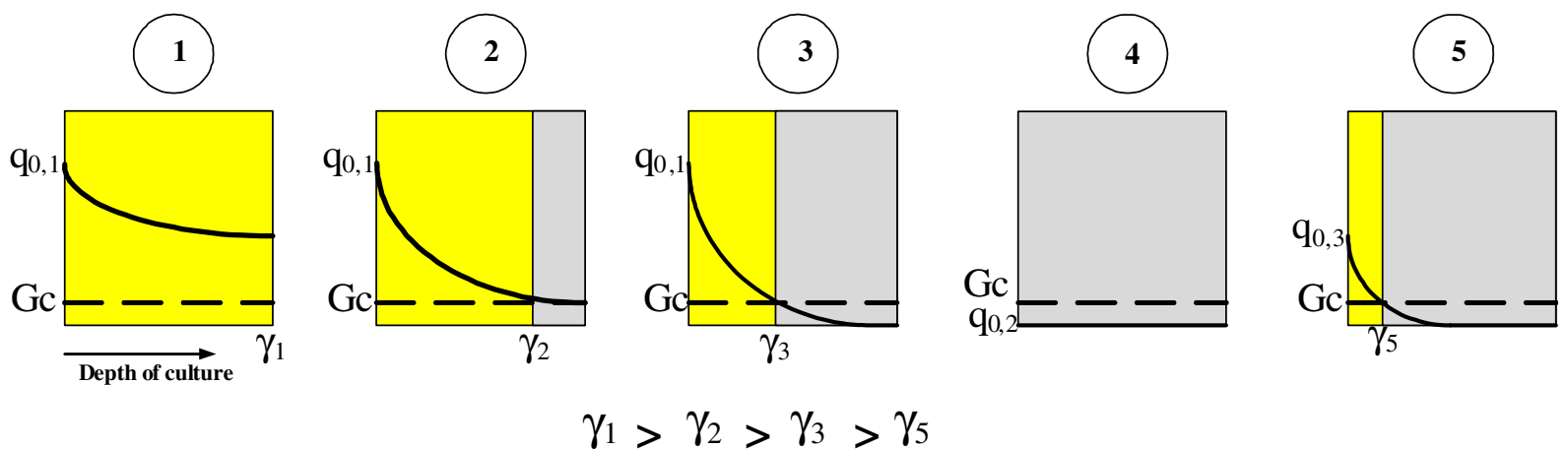

$\gamma_{1}>\gamma_{2}>\gamma_{3}>\gamma_{5}$

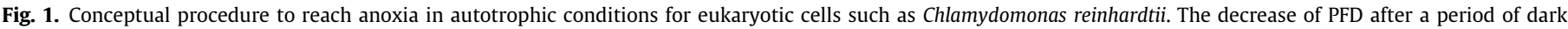
adaptation allows maintaining anoxic conditions under light for a long time. 
result, photosynthetic capacity of the cells is hoped to be not be affected like that is the case for example of sulphur deprivation (Wykoff et al., 1998; Melis et al., 2000).

The procedure is schematically represented in Fig. 1. Algae are first cultivated at a given PFD noted $q_{\mathrm{o}, 1}$. Due to the progressive increase in biomass concentration, light penetration in the culture, as represented by the $\gamma$ value, will reduce. If the initial biomass concentration is insufficient to absorb all the light received (as usually obtained in a beginning of a batch growth), light conditions will start from fully illuminated conditions (Step 1) to have next appearance of a dark zone with full light absorption (Step 2) that will increase progressively to obtain a given value for which the dark zone (respiration) will compensate the illuminated zone resulting in null growth (Step 3 ) or steady-state phase. Steps 1-3 are classical of a light limited batch growth (see Pruvost et al., 2009 for details).

Having a dark zone in the culture volume was a sufficient condition to achieve anoxic conditions in the case of mixotrophic growth with $C$. reinhartdii, but not in autotrophic conditions (Degrenne et al., 2010). If a linear relationship is indeed assumed between biomass growth and oxygen production (a classical assumption of autotrophic growth), the oxygen production rate $\left\langle r_{\mathrm{O}_{2}}\right\rangle$ is minimal and null at the plateau (by definition biomass production rate is also null), but is never negative (and there is thus no net oxygen consumption). Anoxic conditions establishment requests thus additional steps. This can be achieved by shutting down the light $\left(q_{\mathrm{o}, 2}=0\right)$ for a period necessary for algae to consume dissolved oxygen in the medium by respiration. This is usually named the dark adaptation period (Step 4). The culture can then be illuminated again and a hydrogen production will be observed. But this never exceeds several minutes because of the fast oxygen release that inhibits [Fe-Fe]-hydrogenase. Based on the previous reasoning, illumination conditions could however be adapted to maintain anoxic conditions. Because dark adaptation period results in a biomass concentration decrease (cell catabolism), illuminated next the culture (a necessary condition for light induced hydrogen production by photosynthesis) with the same PFD $q_{\mathrm{o}, 1}$ as in the first growth phase will result in a oxygen production (better light penetration and higher $\gamma$ value). So, the maintenance of anoxic conditions will imply to apply a PFD value $q_{\mathrm{o}, 3}$ inferior to $q_{\mathrm{o}, 1}$ to reach an adequate value of the illuminated fraction $\gamma$ leading then to a negative value of $\left\langle r_{\mathrm{O}_{2}}\right\rangle$ despite the illumination applied to the culture (Step 5). As long as this condition will be satisfied, anoxic conditions under illumination will be maintained.

\section{Results}

\subsection{Validation of the protocol}

The protocol presented above has been applied in the torusshape PBR to evaluate its feasibility and its interest for hydrogen production. The experiment was led in autotrophic medium. Results are given in Fig. 2a for both biomass concentration and illuminated fraction. A first growth phase (Phase 1) was applied with a constant PFD $q_{\mathrm{o}, 1}=300 \mu \mathrm{mol} \mathrm{m} \mathrm{m}^{-2} \mathrm{~s}^{-1}$. A plateau was reached after 8 days with a maximal biomass concentration around $2 \mathrm{~kg} \mathrm{~m}^{-3}$ (initial biomass concentration of $0.2 \mathrm{~kg} \mathrm{~m}^{-3}$ ). The progressive increase in biomass concentration results in a progressive decrease of illuminated fraction $\gamma$, with a dark zone $(\gamma<1)$ appearing after 2 days. At the end of this first phase, an asymptotic value of 0.36 was achieved (showing thus that only one third of the culture volume was illuminated). A period of $3 \mathrm{~h}$ of total obscurity $q_{\mathrm{o}, 2}=0$ (Phase 2) was then necessary to reach anoxic conditions (as monitored by dissolved oxygen probe, data not shown). Because dissolved oxygen in the culture medium is consumed by mitochondrial respiration, this results in a decrease of biomass concentration (biomass catabolism) from $2 \mathrm{~kg} \mathrm{~m}^{-3}$ to $1.84 \mathrm{~kg} \mathrm{~m}^{-3}$. When anoxic conditions were achieved, the culture was illuminated again (Phase 3 ) but with a PFD $q_{\mathrm{o}, 3}=110 \mu \mathrm{mol} \mathrm{m} \mathrm{m}^{-2} \mathrm{~s}^{-1}$. The illuminated fraction passed thus from $\sim 0.36$ to $\sim 0.25$.

Influence on gas phase is shown in Fig. 2b. During the initial growth (Phase 1), an important oxygen production was observed (until $16.7 \mathrm{ml} \mathrm{O}_{2} / \mathrm{h} \mathrm{l}$ before to decrease at $t=2$ days, corresponding exactly to the appearance of the dark zone in the PBR and confirming at the same time the direct relation between oxygen production rate and the $\gamma$ value). At $t=8.5$ days, effect of dark adaptation (Phase 2) is also shown with a great reduction in oxygen flow-rate measured in the PBR outlet, as obviously explained by the sudden stop in oxygen photosynthetic production when placing cells in the dark. When the culture was again submitted to a low PFD $q_{\mathrm{o}, 3}=110 \mu \mathrm{mol} \mathrm{m} \mathrm{m}^{-2} \mathrm{~s}^{-1}$ (Phase 3), a low hydrogen production rate was observed during 2 days with a maximum of $0.12 \mathrm{ml} \mathrm{H}_{2} / \mathrm{hl}$ (for practical reason, the cultivation was stopped after 2 days. Longer term experiments are given in next section). It must be stated that during this phase, the oxygen flow-rate measured in PBR outlet is not null, although very low. This is explained here by the fact that photosynthesis is still active with cells still producing oxygen. A part is consumed by respiration in the culture volume, but a part is also retrieved in the PBR outlet. These results in a dissolved oxygen concentration very close to null value (below the probe sensitivity of $0.10 \mathrm{mg} / \mathrm{l}$ ) enabling thus Fe-hydrogenase to be active and hydrogen to be produced. This experiment confirms that anoxic conditions can be easily reached just by controlling the PBR illuminated fraction. In this case, by decreasing $\gamma$ from $\sim 0.36$ to $\sim 0.25$ after a period of $3 \mathrm{~h}$ of dark adaptation, anoxic conditions were maintained and hydrogen was produced during at least 2 days. A measurement of photosynthetic yield confirmed that the photosynthetic capacity of cells was not affected (the ratio $F_{\mathrm{v}} / F_{\mathrm{m}}$ stays always higher than 0.7 , data not shown for this example but given for following experiments). Oxygen was thus still produced by cells (that is coherent with the very small oxygen flow-rate measured in PBR outlet) but the dark zone was sufficiently important to maintain anoxic conditions in culture volume (those specific conditions are also known as hypoxia, as described further in the text).

\subsection{Influence of different values of $\gamma$ on the hydrogen productivity}

Based on the previous validation, another experiment was conducted in the aim to achieve a higher biomass concentration, so as to be able to apply successively different PFDs in the final hydrogen producing phase. Fig. 3a shows the evolution of biomass dry weight inside the PBR and Fig. 3b, the corresponding gas production. Because of the small dry weight concentration $\left(0.2 \mathrm{~kg} \mathrm{~m}^{-3}\right)$, microalgae were grown with a progressive PFD to avoid photoinhibition phenomena. A value of $470 \mu \mathrm{mol} \mathrm{m}^{-2} \mathrm{~s}^{-1}$ was first applied (1) during the first 2 days and then increased to $655 \mu \mathrm{mol} \mathrm{m} \mathrm{m}^{-2} \mathrm{~s}^{-1}$ and (2) until a high weight concentration of $2.2 \mathrm{~kg} \mathrm{~m}^{-3}$. Light source was then shut-down for $3 \mathrm{~h}$ (Phase 2 of the protocol). During this step, dissolved oxygen was consumed by mitochondrial respiration, resulting in a biomass decrease down to $2.1 \mathrm{~kg} \mathrm{~m}^{-3}$. At this moment, anoxic conditions were obtained.

Different PFDs were next successively tested. A PFD of $375 \mu \mathrm{mol} \mathrm{m}{ }^{-2} \mathrm{~s}^{-1}(\gamma \sim 0.38)$ (3) was firstly applied. Hydrogen production (Fig. 3b) was observed but oxygen was rapidly released, inhibiting its production. Hydrogen production stopped only after $5 \mathrm{~h}$ of illumination. Same results were obtained with PFD of $295 \mu \mathrm{mol} \mathrm{m}^{-2} \mathrm{~s}^{-1}(\gamma \sim 0.35)$ and $225 \mu \mathrm{mol} \mathrm{m}^{-2} \mathrm{~s}^{-1}(\gamma \sim 0.31)$ (3). During those investigations, biomass concentration decreased from $2.1 \mathrm{~kg} \mathrm{~m}^{-3}$ to $2 \mathrm{~kg} \mathrm{~m}^{-3}$ showing that PFD value were insufficient to increase biomass concentration, but also insufficient to 


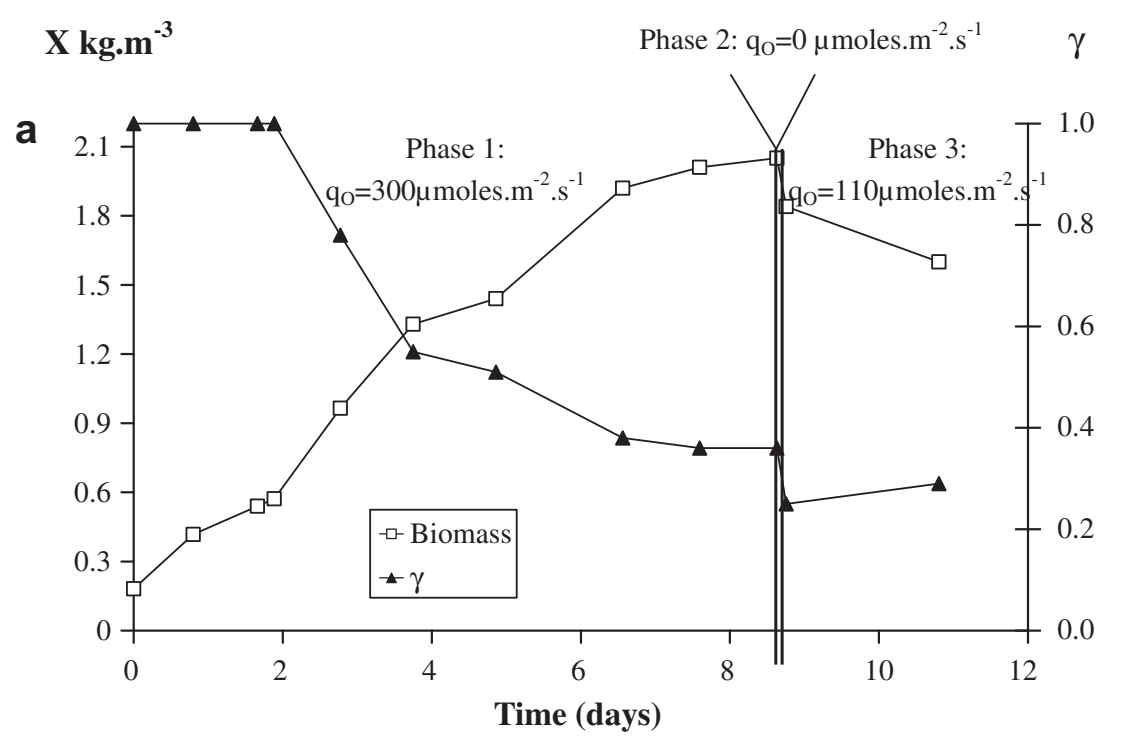

$\mathbf{r}_{\mathrm{O} 2} \mathrm{ml} / \mathrm{h} . \mathrm{L}$

$\mathbf{r}_{\mathrm{H} 2} \mathbf{m l} / \mathbf{h} . \mathrm{L}$

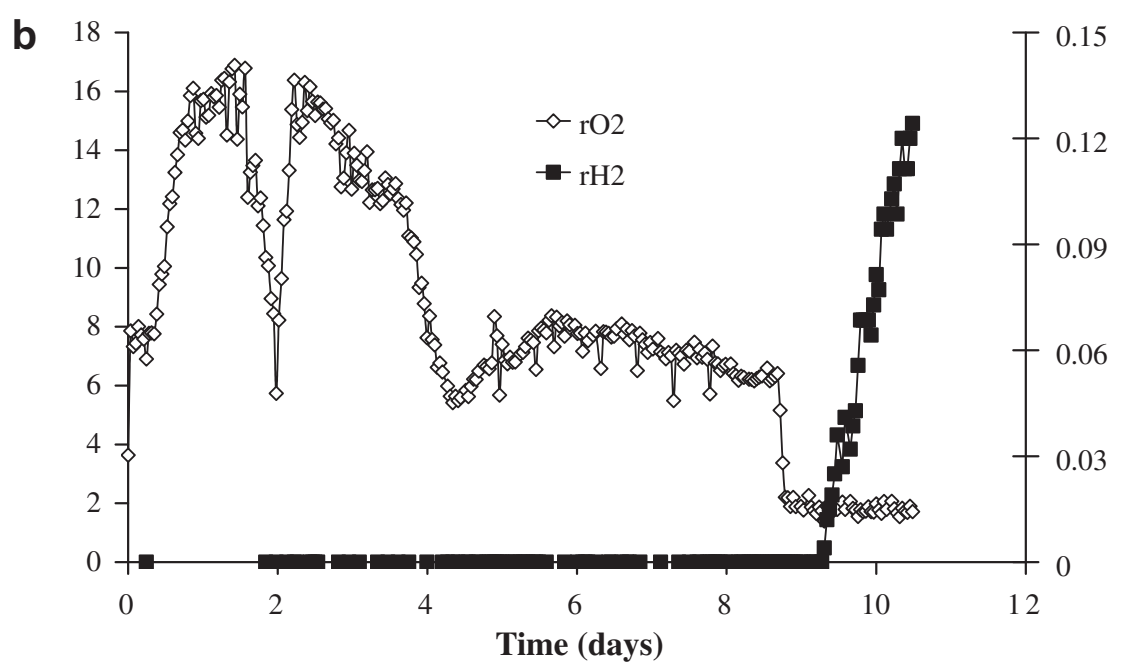

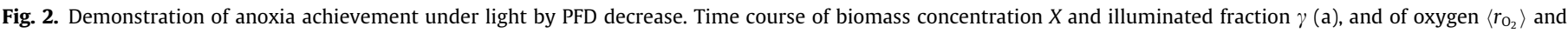
hydrogen $\left\langle r_{\mathrm{H}_{2}}\right\rangle$ gas production (b). Hydrogen production is observed after the induction of anaerobic conditions in dark.

maintain anoxic conditions for a long duration, the biomass decrease resulting then in an increase of the illuminated fraction $\gamma$ up to a value resulting in oxygen production for these PFD. A lower PFD of $160 \mu \mathrm{mol} \mathrm{m}^{-2} \mathrm{~s}^{-1}(\gamma \sim 0.28)(4)$ was then applied after another dark period to retrieve anoxic conditions. In this condition, anoxia was maintained during $38 \mathrm{~h}$ and hydrogen gas production was observed with an averaged flow-rate of $0.3 \mathrm{ml} \mathrm{H}_{2} / \mathrm{h} 1$. Biomass concentration decreased during this period from $2 \mathrm{~kg} \mathrm{~m}^{-3}$ to $1.83 \mathrm{~kg} \mathrm{~m}^{-3}$. When this last value was reached, light attenuation was not sufficient and anoxia was again disrupted, resulting in an inhibition of hydrogen release. A final PFD value was thus applied, with a decrease to $135 \mu \mathrm{mol} \mathrm{m}^{-2} \mathrm{~s}^{-1}(\gamma \sim 0.26)$ (5). Anoxic conditions were then maintained during $144 \mathrm{~h}$ and hydrogen production was again observed. Hydrogen was firstly released with an averaged flow-rate of $0.22 \mathrm{ml} \mathrm{H}_{2} / \mathrm{hl}$ during $38 \mathrm{~h}$, but this production increased suddenly 17 day, Fig. $3 b$ up to a maximum rate of $1.01 \mathrm{ml} \mathrm{H}_{2} / \mathrm{hl}\left(0.8 \pm 0.2 \mathrm{~mL} \mathrm{H}_{2} / \mathrm{h} / \mathrm{g}\right.$ of biomass $)$. In the same time, biomass concentration decreased from $1.83 \mathrm{~kg} \mathrm{~m}^{-3}$ to $1 \mathrm{~kg} \mathrm{~m}^{-3}$, to stabilize next until the end of the experiment showing that the steady-state concentration corresponding to this PFD was almost achieved. During the last 2 days, low hydrogen production was observed with a small rate of $0.04 \mathrm{ml} \mathrm{H}_{2} / \mathrm{h} \mathrm{l}$ and no oxygen production was observed.

The experiment confirmed that controlling light attenuation conditions by adjusting the PFD was sufficient to maintain anoxic conditions and produce hydrogen in autotrophic conditions. Because of the progressive biomass decrease due to respiration catabolism, it was necessary to adapt the PFD in accordance. In this case, a long duration hydrogen production was achieved. For the longer period investigated, it was observed an important and sudden hydrogen production peak ( $t=17$ days). As shown in Fig. 3c, this coincides also with a high decrease in the maximal photosynthetic yield $\left(F_{\mathrm{v}} / F_{\mathrm{m}}\right)$. This could be explained by a mineral starvation, as for example sulphur deprivation which reduces $\mathrm{PS}_{\mathrm{II}}$ activity but, as already said, no mineral limitation occurred in our experiment (this was checked using anionic chromatography, giving values of nitrogen, phosphorus and sulphur sources higher than $60 \mathrm{mg} / \mathrm{l}$ ). This is also interesting to correlate this result with the biomass composition evolution (total proteins, total sugars and starch contents) as shown in Fig. 3c. During the experiment, total sugars, as a classical response of nutrient starvation, were not accumulated $(13.7 \%$ and $4 \%$ of the 
a Biomass

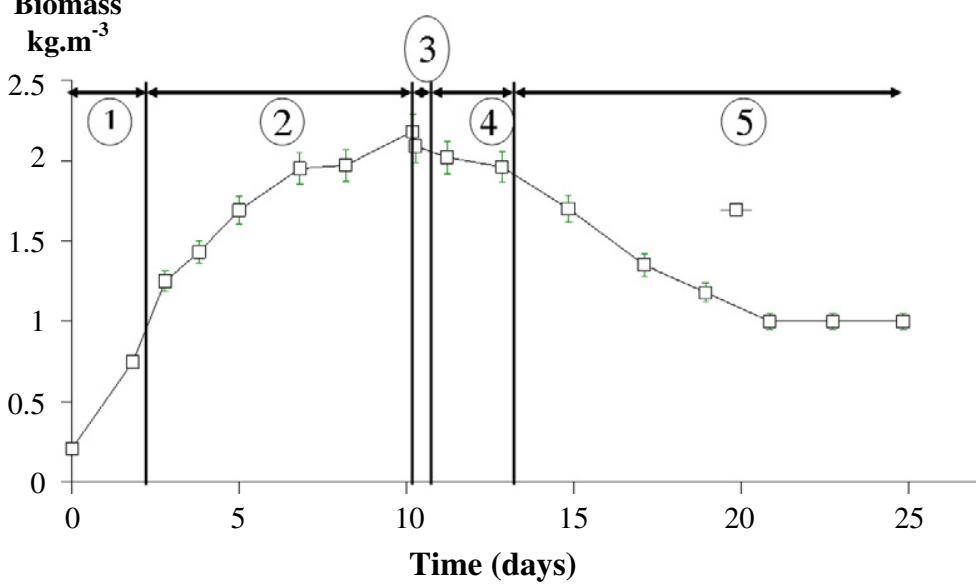

b $\mathrm{rO}_{2} \mathrm{ml} \mathrm{O2/h.L}$

$\mathbf{r H}_{2} \mathrm{ml} \mathrm{H2} / \mathrm{h} . \mathrm{L}$

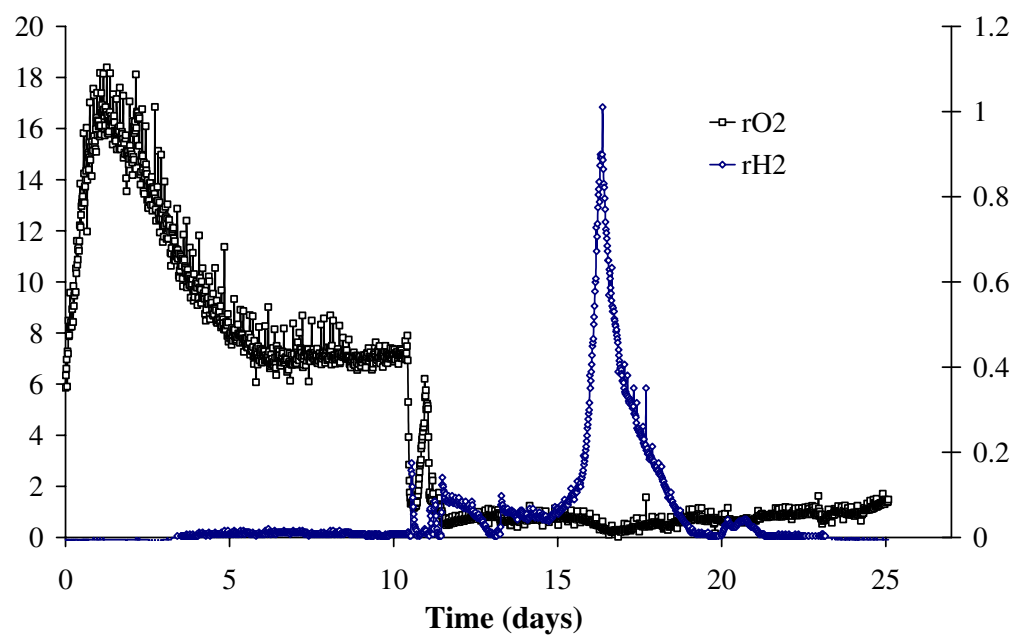

C

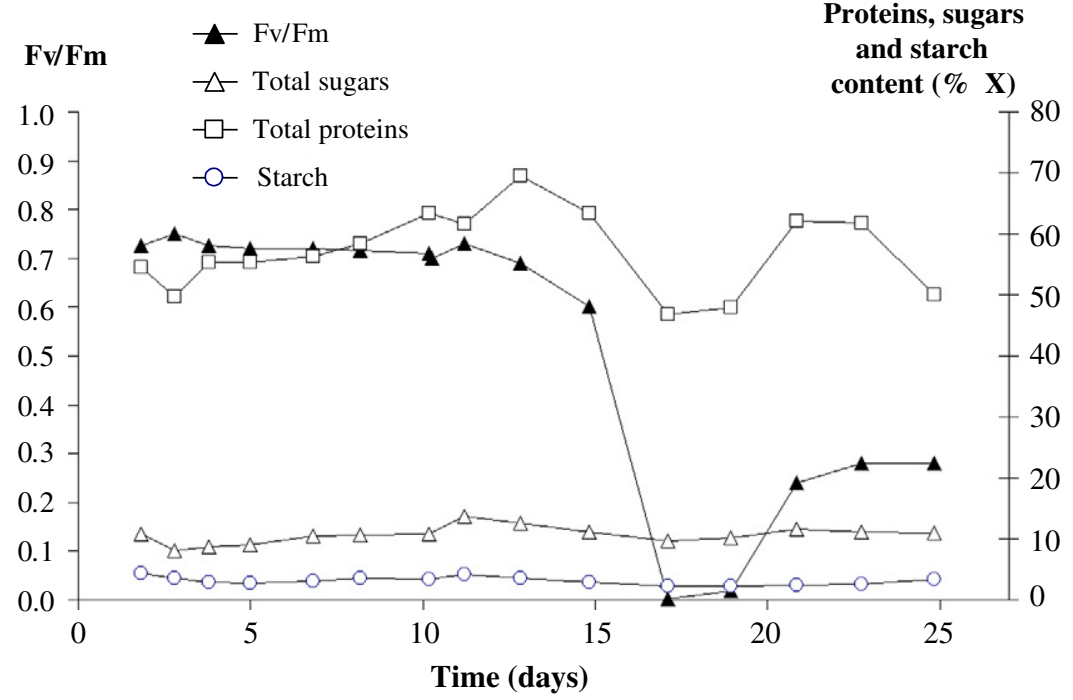

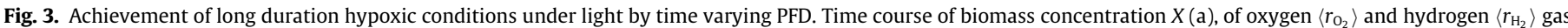

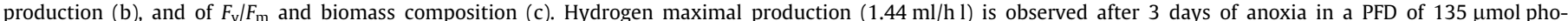
tons $\mathrm{m}^{-2} \mathrm{~s}^{-1}$, concomitant of a brutal decrease of $F_{\mathrm{v}} / F_{\mathrm{m}}$ and proteins content.

total dry weight for total sugars and starch maximal contents, respectively). In contrary, a small degradation (9.7\% of the total dry weight for total sugars) was obtained at the 17th day. For total proteins that represent about $60 \%$ of total dry weight dur- ing growth stage, an abrupt decrease was observed, from $63.4 \%$ to $46.7 \%$ of the dry weight between the 15 th and 17 th days. This protein degradation seems thus highly correlated to the hydrogen release. 
4.3. Effect of prolonged anoxic conditions on algae with over-accumulation of starch

Because starch is known to play a major role in the hydrogen production in green algae (Melis et al., 2000; Fouchard et al., 2005; Chochois et al., 2009), the previous protocol was applied on cells having previously over-accumulated starch under nitrogen depletion. This nitrogen limitation was lead in the PBR operated in continuous chemostat mode. Continuous culture allows to obtain a reproducible steady-state with a culture having a given concentration and physiological state. This was used here in order to stabilize starch cellular content before starting each experiment. Incidently, by adjusting the level of nitrogen limitation, different starch content were obtained at the beginning of each experiment in prolonged anoxic and hydrogen producing conditions.

As a reference, cells without starch over-accumulation were firstly obtained by applying a PFD of $800 \mu \mathrm{mol} \mathrm{m}^{-2} \mathrm{~s}^{-1}$ with a dilution rate of $0.01 \mathrm{~h}^{-1}$. Under these conditions, biomass concentration stabilized at $2.0 \mathrm{~kg} \mathrm{~m}^{-3}$ with a composition of $60 \%, 23 \%$ and $4 \%$ in proteins, total sugars and starch content, respectively. A mass balance on nitrogen source (ammonium) was conducted, resulting in a yield of consumption of $320 \mathrm{mg}$ of $\mathrm{NH}_{4}^{+} / \mathrm{g}$ of dry weight biomass.
To obtain cells with a starch over-accumulation, the feeding medium was modified concerning nitrogen concentration, with a limited concentration of $435 \mathrm{mg} / \mathrm{l}$ of $\mathrm{NH}_{4}^{+}$. A PFD value of $1070 \mu \mathrm{mol} \mathrm{m} \mathrm{m}^{-2} \mathrm{~s}^{-1}$ with a dilution rate of $0.008 \mathrm{~h}^{-1}$ was then applied. Due to this higher PFD and lower dilution rate, a biomass concentration of $1.6 \mathrm{~kg} \mathrm{~m}^{-3}$ as in the non limited continuous culture was obtained, but with a nitrogen limitation (regarding the yield of consumption, such biomass concentration requests a feeding concentration around $580 \mathrm{mg} / \mathrm{l}$ in $\mathrm{NH}_{4}^{+}$). This was confirmed by a starch over-accumulation of $9 \pm 0.5 \%$ of the biomass dry weight (instead of $4 \%$ for cells without limitation).

When each of the steady-state concentrations previously described was achieved, the protocol based on PFD modifications was applied (batch conditions), with dark adaptation during 3$\mathrm{h}$ (biomass concentration decrease from $2.0-1.7 \mathrm{~kg} \mathrm{~m}^{-3}$ to $1.8-$ $1.5 \mathrm{~kg} \mathrm{~m}^{-3}$ in each case) and then a low PFD of $50 \mu \mathrm{mol} \mathrm{m}^{-2} \mathrm{~s}^{-1}$ to maintain anoxic conditions during 12 days. Fig. $4 a$ gives the evolution of biomass concentration and of the maximum photosynthetic yield and Fig. $4 \mathrm{~b}$, the result for hydrogen production. The over-accumulation of starch revealed to have a positive influence on hydrogen production, but only during the 1st day of anoxic conditions. In these conditions, a maximal productivity of $0.38 \mathrm{ml} \mathrm{H}_{2} / \mathrm{hl}$ was obtained. Because of the value of PFD

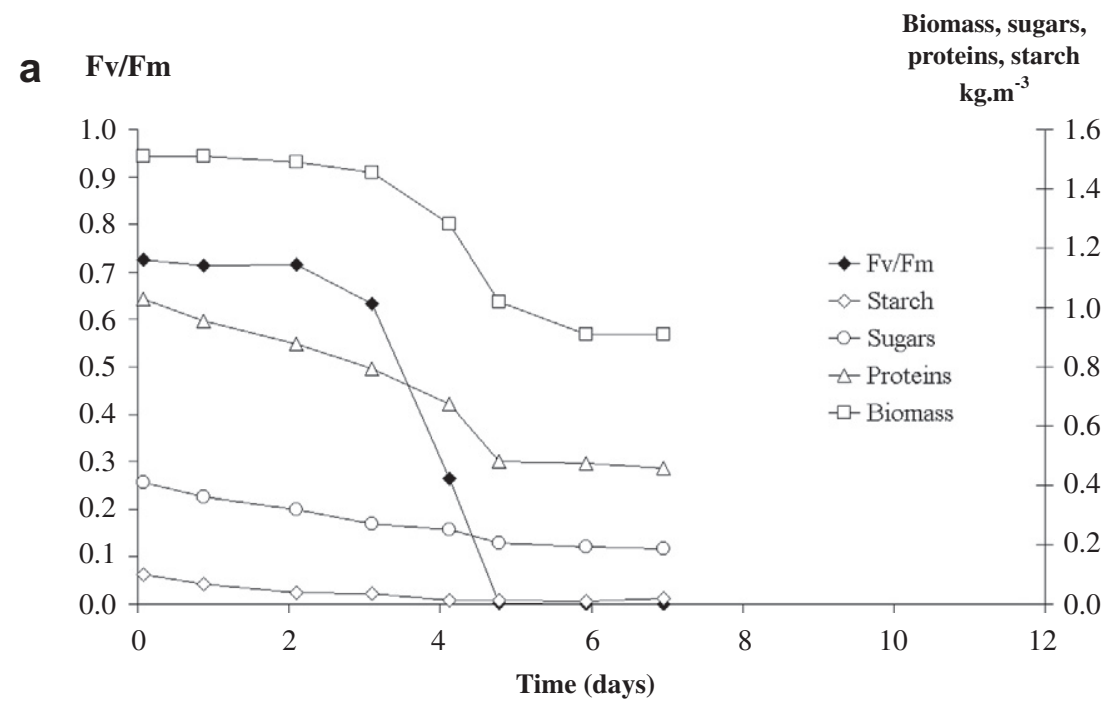

$\mathrm{ml} \mathrm{H} / \mathrm{h} . \mathrm{L}$

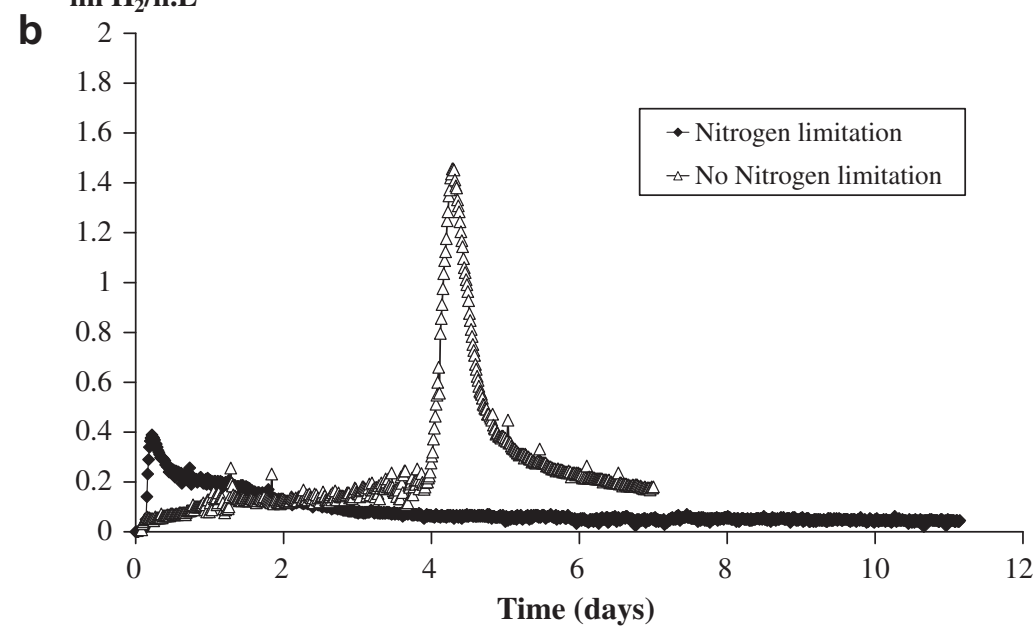

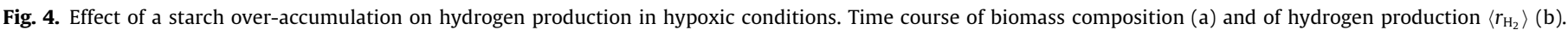

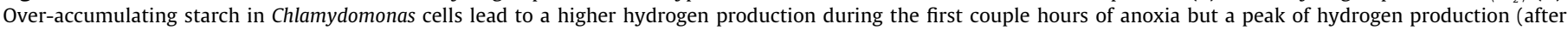
4 days) of culture is observed only in cells having not over-accumulated starch. 
retained, anoxic conditions was maintained here during 11 days. The peak of hydrogen production of $1.44 \mathrm{ml} \mathrm{H}_{2} / \mathrm{h} \mathrm{l}$ ( $1.08 \pm 0.21 \mathrm{ml} \mathrm{H}_{2} / \mathrm{h} / \mathrm{g}$ of biomass) was again observed after 4.5 days, but only for cells having not previously over-accumulated starch. This peak corresponded again with a sudden evolution in biomass concentration with a decrease after 4 days (from the 4th to 8th day) from $1.5 \mathrm{~kg} \mathrm{~m}^{-3}$ down to $0.9 \mathrm{~kg} \mathrm{~m}^{-3}$, with a catabolism of proteins (and in a less extent sugars) and with a decrease of the maximum photosynthetic yield $F_{\mathrm{v}} / F_{\mathrm{m}}$ (Fig. $4 \mathrm{a}$ ). For the cells having not over-accumulated starch, such sudden degradation is not observed, confirming the relation between the peak of hydrogen production and the important changes in cell metabolism and composition that occur simultaneously.

\section{Discussion}

Although hydrogen production by the green microalga $C$. reinhardtii was mainly investigated in mixotrophic conditions (medium containing acetate), a part of the scientific effort was recently focused on hydrogen production in autotrophic conditions because of its evident environmental interest (the consumption of an organic source leading to $\mathrm{CO}_{2}$ release). In autotrophic conditions, anoxic conditions were found however more difficult to obtain (Fouchard et al., 2005). A successful protocol was proposed by Tsygankov et al. (2006) where sulphurdeprivation protocol was associated with a reduction of incident PFD. These conditions allow increasing starch content, maintaining anoxic conditions and then producing hydrogen. Recent improvements were tested to increase starch accumulation (Tolstygina et al., 2009). Our study presents an extension of these studies, by setting the production of hydrogen in autotrophic conditions by the strict and only control of illuminated fraction $\gamma$ in the PBR (by means of PFD adjustment). The culture reached in a first batch growth phase a maximum biomass concentration with corresponding $\gamma$ value close to 0.34 . If oxygen in the medium was consumed after a period of dark adaptation, the dropping of PFD to obtain a $\gamma$ value below $\sim 0.25$ revealed to be sufficient to maintain anoxic conditions under illumination conditions, enabling hydrogen production. By maintaining during several days anoxic conditions, a low but continuous hydrogen productivity was obtained during the first day (around $0.3 \mathrm{ml} \mathrm{H}_{2} / \mathrm{hl}$ ). But after 3 days, a peak of hydrogen production was also observed. This peak, never mentioned in literature in the authors' knowledge, was concomitant with a sudden decrease of biomass concentration as well as degradation of both maximal photosynthetic yield and protein content (and in a less extent total sugars). Maximal hydrogen production was found sevenfold higher than the previous one (around to $1.44 \mathrm{ml} \mathrm{H}_{2}$ / hl) but still lower than value $\left(3.5 \mathrm{ml} \mathrm{H}_{2} / \mathrm{hl}\right.$ ) reached in sulphur-deprivation protocol in mixotrophic conditions (Melis et al., 2000). An additional experiment with cells having previously over-accumulated starch confirmed that increasing the starch content allows reaching higher hydrogen productivities during the 1st day of anoxic conditions by probably increasing the PSII-independent pathway. This was already stated in literature, but surprisingly, the peak of hydrogen production (with the concomitant decrease in biomass concentration, maximal photosynthetic yield and proteins content) was only observed for cells having not over-accumulated starch.

The physiological explanation of the hydrogen peak is not clear and it would have to be more deeply investigate in the future. It is known that hydrogen production during sulphur deprivation is due to an excess of electrons in the photosynthetic chain and is a specific metabolism for cells to survive in the particular conditions of anoxia (Hemschemeier et al., 2008). But conditions investigated here are highly different, the PSII activity being not impaired by sulphur deprivation when anoxia is reached. In our case, the source of electrons and protons for hydrogen production cannot be identified regarding only the results provided in this study. But the proteins catabolism plays certainly an important role as being simultaneously observed from the hydrogen peak. It has indeed already been shown that proteins were a potential source of electrons for hydrogen production because of the relationship between the catabolism of Rubisco and starch accumulation (White and Melis, 2006). Our results are in agreement although no specific over-accumulation of starch was observed. This could also explain why no hydrogen peak occurred for nitrogen limited cells having over-accumulated starch, those cells having also a lower protein content than fresh cells.

The role of the high decrease of maximal photosynthetic yield should also be more deeply investigated. Its partial recovery after the hydrogen peak seems to indicate a possible reorganization of cellular metabolism up to $\mathrm{PS}_{\mathrm{II}}$ activity, triggered here by a long period of illumination in anoxic conditions. Literature confirms indeed that a lot of biochemical pathways or genetical rearrangement can occur when photosynthetical cells are in hypoxia, those rearrangements interacting certainly with the hydrogen production. This was already related in some studies where it was found multiple responses when $C$. reinhardtii cells were in oxygen deficient conditions (Quinn et al., 2000; Moseley et al., 2000; Quinn et al., 2002; Vaas et al., 1992). Some important genetical regulations or specific physiological responses were found as, for example the synthesis of a putative di-iron enzyme ([Fe-Fe]-hydrogenase) or the modification in the traduction of some enzymes of the photosynthetic chain (cytochrome c6, D1 protein). [Fe-Fe]-hydrogenase and the photosynthetic chain being implied in hydrogen production, relationships with related biochemical pathways could exist. But this remains to be more deeply investigated. It must be indeed pointed out that such environmental conditions used in this study are very specific. Anoxic, autotrophic and limited illuminated conditions are rarely encountered simultaneously by cells being not impaired in their photosynthetic activity (especially during several days). This is permitted here by the control of culture conditions allowed especially the radiation field in the PBR. Anoxic conditions can be maintained for a long duration due to cell catabolism and mitochondrial respiration when an illuminated fraction around. But even if the condition of under illumination leads to oxygen consumption and thus anoxia in the culture volume, only partial anoxia is certainly encountered at the cell level, cells being always able to produce photosynthetic oxygen when receiving light (as in the illuminated zone). This hypoxic metabolism (hypoxia describes growth under limited amount of oxygen) could thus involve possible specific metabolic response, possibly interacting with the hydrogen pathways. This important aspect will request specific investigations.

\section{Conclusion}

Hydrogen production was investigated for $C$. reinhardtii in autotrophic conditions and prolonged hypoxic conditions. This was obtained in a torus PBR by only time varying the PFD, to maintain adequate radiative transfer conditions. After several days of constant hydrogen release, a peak of hydrogen production was also observed, concomitant with an important biomass catabolism and maximal photosynthetic yield decrease. Although lower than the productivity usually observed in literature, this production peak was never stated before of our knowledge. It was certainly related to the particular conditions of long duration hypoxia, involving specific metabolic responses possibly interacting with the hydrogen producing pathways. 


\section{Acknowledgements}

This work was supported by the European FP7 research program "SolarH2", the French program ANR"Photobioh2" and by a grant of the French region "Pays de la Loire".

\section{References}

Benemann, J.R., Berenson, J.A., Kaplan, N.O., Kamen, M.D., 1973. Hydrogen evolution by a chloroplast-ferredoxin-hydrogenase system. Proceedings of the National Academy of Sciences of the United States of America 70 (8), 2317-2320.

Chochois, V., Dauvillée, D., Beyly, A., Tolleter, D., Cuiné, S., Timpano, H., Ball, S. Cournac, L., Peltier, G., 2009. Hydrogen production in Chlamydomonas: PSIIdependent and independent pathways differ in their requirement on starch metabolism. Plant Physiology 151, 631-640.

Cornet, J.F., Dussap, C.G., Cluzel, P., Dubertret, G., 1992. A structured model for simulation of cultures of the cyanobacterium Spirulina platensis in photobioreactors. 2. Identification of kinetic parameters under light and mineral limitations. Biotechnology and Bioengineering 40 (7), 826-834.

Cornet, J.F., Dussap, C.G., 2009. A simple and reliable formula for assessment of maximum volumetric productivities in photobioreactors. Biotechnology Progress 25 (4), 424-435.

Cournac, L., Mus, F., Bernard, L., Guedeney, G., Vignais, P., Peltier, G., 2002. Limiting steps of hydrogen production in Chlamydomonas reinhardtii and Synechocystis PCC 6803 as analysed by light-induced gas exchange transients. Internationa Journal of Hydrogen Energy 27 (11-12), 1229-1237.

Degrenne, B., Pruvost, J., Christophe, G., Cornet, J.-F., Cogne, G., Legrand, J., 2010 Investigation of the combined effects of acetate and photobioreactor illuminated fraction in the induction of anoxia for hydrogen production by Chlamydomonas reinhardtii. International Journal of Hydrogen Energy.

Dubois, M., Gilles, K.A., Hamilton, J.K., Rebers, P.A., Smith, F., 1956. Colorimetric method for determination of sugars and related substances. Analytica Chemistry 28 (3), 350-356.

Endo, T., Asada, K., 1996. Dark induction of the non-photochemical quenching of chlorophyll fluorescence by acetate in Chlamydomonas reinhardtii. Plant and Cel Physiology 37 (4), 551-555.

Fouchard, S., Hemschemeier, A., Caruana, A., Pruvost, J., Legrand, J., Happe, T., Peltier, G., Cournac, L., 2005. Autotrophic and mixotrophic hydrogen photoproduction in sulfur-deprived Chlamydomonas cells. Applied and Environmental Microbiology 71 (10), 6199-6205.

Fouchard, S., Pruvost, J., Degrenne, B., Legrand, J., 2008. Investigation of $\mathrm{H}_{2}$ production using the green microalga Chlamydomonas reinhardtii in a fullycontrolled photobioreactor fitted with on-line gas analysis. International Journal of Hydrogen Energy 33 (13), 3302-3310.

Gaffron, H., Rubin, J., 1942. Fermentative and photochemical production of hydrogen in algae. Journal of General Physiology 26 (2), 219-240.

Ghirardi, M.L., Posewitz, M.C., Maness, P.-C., Dubini, A., Yu, J.P., Seibert, M., 2007. Hydrogenases and hydrogen photoproduction in oxygenic photosynthetic organisms. Annual Review of Plant Biology 58, 71-91.

Guo, Z., Chen, Z., Zhang, W., Yu, X., Jin, M., 2008. Improved hydrogen photoproduction regulated by carbonylcyanide $m$-chlorophenylhydrazone from marine green alga Platymonas subcordiformis grown in $\mathrm{CO}_{2}$-supplemented air bubble column bioreactor. Biotechnology Letters. 30 (5), 877-883.

Hamada, E.A.M., Dowiadar, S.M.A., Punnet, T., 2003. Influence of spectral range and carbon and nitrogen sources on oxygen evolution and Emerson enhancement in Chlamydomonas reinhardtii. Biologica Plantarium 46 (3), 389-397.

Heifetz, P.B., Forster, B., Osmond, C., Giles, L., Boynton, J.E., 2000. Effects of acetate on facultative autotrophy in Chlamydomonas reinhardtii assessed by photosynthetic measurements and stable isotope analyses. Plant Physiology 122 (4), 1439-1445.

Hemschemeier, A., Fouchard, S., Cournac, L., Peltier, G., Happe, T., 2008. Hydrogen production by Chlamydomonas reinhardtii: an elaborate interplay of electron sources and sinks. Planta 227 (2), 397-407.

Klein, U., Betz, A., 1978. Fermentative metabolism of hydrogen-evolving Chlamydomonas moewusii. Plant Physiology 61 (6), 953-956.

Kojima, E., Lin, B., 2004. Effect of partial shading on photoproduction of hydrogen by chlorella. Journal of Bioscience and Bioengineering 95 (5), 317-321.
Kosourov, S., Makarova, V., Fedorov, A.S., Tsygankov, A., Seibert, M., Ghirardi, M.L., 2005. The effect of sulfur re-addition on $\mathrm{H}-2$ photoproduction by sulfurdeprived green algae. Photosynthesis Research 85 (3), 295-305.

Kosourov, S., Patrusheva, E., Ghirardi, M.L., Seibert, M., Tsygankov, A., 2007. A comparison of hydrogen photoproduction by sulfur-deprived Chlamydomonas reinhardtii under different growth conditions. Journal of Biotechnology 128 (4), 776-787.

Lowry, O.H., Rosebrough, N.J., Farr, A.L., Randall, R.J., 1951. Protein measurement with the Folin phenol reagent. Journal of Biological Chemistry 193 (1), 265275 .

Makarova, V.V., Kosourov, S., Krendeleva, T.E., Semin, B.K., Kukarskikh, G.P., Rubin, A.B. Sayre, R.T., Ghirardi, M.L., Seibert, M., 2007. Photoproduction of hydrogen by sulfur-deprived $C$. reinhardtii mutants with impaired photosystem II photochemical activity. Photosynthesis Research 94 (1), 79-89.

Markov, S.A., Eivazova, E.R., Greenwood, J., 2006. Photostimulation of H-2 production in the green alga Chlamydomonas reinhardtii upon photoinhibition of its O-2-evolving system. International Journal of Hydrogen Energy 31 (10), 1314-1317.

Melis, A., Zhang, L.P., Forestier, M., Ghirardi, M.L., Seibert, M., 2000. Sustained photobiological hydrogen gas production upon reversible inactivation of oxygen evolution in the green alga Chlamydomonas reinhardtii. Plant Physiology 122 (1), 127-136.

Melis, A., 2002. Green alga hydrogen production: progress, challenges and prospects. International Journal of Hydrogen Energy 27 (11-12), 1217-1228.

Moseley, J., Quinn, J., Eriksson, M., Merchant, S., 2000. The Crd1 gene encodes a putative di-iron enzyme required for photosystem I accumulation in copper deficiency and hypoxia in Chlamydomonas reinhardtii. European Molecular Biology Organization 19 (10), 2139-2151.

Pottier, L., Pruvost, J., Derernetz, J., Cornet, J.-F., Legrand, J., Dussap, C.-G., 2005. A fully predictive model for one-dimensional light attenuation by Chlamydomonas reinhardtii in a torus photobioreactor. Biotechnology and Bioengineering 91 (5), 569-582.

Pow, T., Krasna, A.I., 1979. Photoproduction of hydrogen from water in hydrogenase-containing algae. Archives of Biochemistry and Biophysics 194 (2), 413-421.

Pruvost, J., Van Vooren, G., Cogne, G., Legrand, J., 2009. Investigation of biomass and lipids production with Neochloris oleoabundans in photobioreactor. Bioresource Technology 100, 5988-5995

Quinn, J., Barraco, P., Eriksson, M., Merchant, S., 2000. Coordinate copper- and oxygen-responsive cyc6 and Cpx1 expression in chlamydomonas is mediated by the same element. The Journal of Biological Chemistry 275 (9), 6080-6089.

Quinn, J., Eriksson, M., Moseley, J., Merchant, S., 2002. Oxygen deficiency responsive gene expression in Chlamydomonas reinhardtii through a copper-sensing signal transduction pathway. Plant Physiology 128, 463-471.

Takache, H., Christophe, G., Cornet, J.F., Pruvost, J., 2010. Experimental and theoretical assessment of maximum productivities for the micro-algae Chlamydomonas reinhardtii in two different geometries of photobioreactors. Biotechnology Progress 26 (2), 431-440.

Tolstygina, I.V., Antal, T.K., Kosourov, S.N., Krendeleva, T.E., Rubin, A., Tsygankov, A.A., 2009. Hydrogen production by photoautotrophic sulfur-deprived Chlamydomonas reinhardtii pre-grown and incubated under high light. Biotechnology and Bioengineering 102 (4), 1055-1061.

Tsygankov, A., Kosourov, S., Tolstygina, I., Ghirardi, M.L., Seibert, M., 2006. Hydrogen production by sulfur-deprived Chlamydomonas reinhardtii under photoautotrophic conditions. International Journal of hydrogen Energy 31 (SI), 1574-1584.

Vaas, I., Styring, S., Hundal, T., Koivuniemi, A., Aro, E., Andersson, B., 1992. Reversible and irreversible intermediates during photoinhibition of photosystem II: stable reduced $Q_{A}$ species promote chlorophyll triplet formation. Proceedings of the National Academy of Sciences of the United States of America 89, 1408-1412.

White, A., Melis, A., 2006. Biochemistry of hydrogen metabolism in Chlamydomonas reinhardtii wild type and a Rubisco-less mutant. International Journal of Hydrogen Energy 31 (4), 455-464.

Wykoff, D.D., Davies, J.P., Melis, A., Grossman, A.R., 1998. The regulation of photosynthetic electron transport during nutrient deprivation in Chlamydomonas reinhardtii. Plant Physiology 117 (1), 129-139.

Zhang, L.P., Melis, A., 2002. Probing green algal hydrogen production. Philosophical Transactions of the Royal Society of London Series B - Biological Sciences 357 (1426), 1499-1507. 